\title{
Modelling the effect of individual strategic behaviour on community-level outcomes of conservation interventions
}

\author{
AIDAN KEANE ${ }^{1 *}$, JULIA P. G. JONES ${ }^{2}$ AND E. J. MILNER-GULLAND ${ }^{1}$ \\ ${ }^{1}$ Department of Life Sciences and Centre for Environmental Policy, Imperial College London, Silmood Park Campus, Ascot SL5 7PY, UK, and \\ ${ }^{2}$ School of the Environment, Natural Resources and Geography, Bangor University, Bangor LL57 2UW, UK
}

Date submitted: 21 October 2011; Date accepted: 23 February 2012; First published online: 18 May 2012

\section{SUMMARY}

Many conservation interventions seek to change resource users' behaviour through the creation and enforcement of rules. Their success depends on changing the incentives of potential rule-breakers and those who monitor and enforce compliance. Project implementers may use payments to encourage monitoring and sanctions to deter rule breaking but there has been little research to examine the effectiveness of such approaches in promoting compliance with conservation rules. The effects of payments and sanctions on poaching in a hypothetical community-based conservation project were investigated using an individual-based model incorporating individual heterogeneity and a realistic range of behaviours. Individuals could choose to poach, monitor others' behaviour, or 'cheat' (claim a fee without actually monitoring behaviour). They could also invest in avoidance to reduce their probability of being detected breaking rules. Community-level outcomes emerged from individuals' choices and strategic interactions. The model demonstrates that payments and sanctions can interact strongly with one another and that their effects depend on the economic context in which they are applied. Sanctions were more reliable than payments in reducing poaching and, in some circumstances, payments produced perverse effects. It is thus important to consider individual-level heterogeneity and strategic decision-making when designing interventions aimed at changing human behaviour.

Keymords: agent based model, community conservation, compliance, incentives, poaching, rule enforcement

\section{INTRODUCTION}

Conservation interventions are increasingly being devolved to the community level (see for example Hackel 1999; Holmern et al. 2007), while payments for ecosystem services (PES) schemes use tangible benefits and sanctions to manipulate

\footnotetext{
${ }^{*}$ Correspondence: Dr Aidan Keane Present address: Department of Anthropology, University College London, 14 Taviton Street, London WC1H 0BW, UK and Institute of Zoology, Regent's Park, London NW1 4RY, UK, e-mail: aidan.keane@ucl.ac.uk
}

the incentives for individuals to behave in particular ways (Sommerville et al. 2009). The outcomes of such interventions emerge through the aggregation of their effects on individuals' decision-making. However community-based conservation is commonly criticized for failing to take account of the heterogeneous nature of communities and the differing incentives of individuals within them (Agrawal \& Gibson 1999; Berkes 2004). As a result, there is a pressing need to develop a better understanding of the incentives faced by individuals, and how they can be modified to produce community-level conservation outcomes.

Rules are ubiquitous in conservation and resource management, and essential for their success (Ostrom 1990; Gibson et al. 2005; Keane et al. 2008), yet the question of how best to design and enforce systems of rules governing local-level resource use has been particularly neglected in conservation research (Robinson et al. 2010). To predict the effects of an enforcement regime, it is not only necessary to understand how an intervention affects the choices of potential rule breakers, but also how it influences the behaviour of those responsible for monitoring non-compliance, and how these decisions interact (Akella \& Canon 2004). In community-based conservation, each person can choose whether to break conservation rules and whether to monitor and report rule breaking (although many community schemes also incorporate elements of top-down approaches where the roles of monitor and rule breaker are generally more clearly delineated). Strategic interactions are therefore likely to occur between individuals, since the costs and benefits of monitoring or rule breaking depend on the prevalence of these behaviours in the rest of the community (Gibson \& Marks 1995; Mesterton-Gibbons \& Milner-Gulland 1998). Furthermore, although community members may face the same choices, differences in individuals' characteristics and motivations may cause them to respond to incentives very differently. Failing to acknowledge these complexities in the design of externally imposed interventions risks unintended consequences.

Models of enforcement and compliance have generally assumed that individuals are influenced by their perceptions of the risk of punishment and the potential rewards (Garoupa 1997; Keane et al. 2008). Few of these models have incorporated heterogeneity in individual characteristics, but the aggregate effect of individual differences in behaviour may have important consequences for conservation outcomes. For example, the returns to a hunter from a day's hunting depend upon their skill at catching animals (Walker et al. 
2002), their choice of hunting strategy (Kümpel et al. 2009) and the resources at their disposal (such as guns and cartridges or wire for snares; Hill \& Kintigh 2009). These factors vary from one hunter to the next, and can cause large individual differences in hunting success (Kümpel et al. 2009), meaning that poaching may be intrinsically more attractive to some individuals than others. Other forms of heterogeneity may produce similar effects. For example, decisions about whether to poach might vary according to an individual's opportunity costs (Damania et al. 2005), with those who are able to find regular paid employment potentially facing lesser incentives to hunt (Muchaal \& Ngandjui 1999), or according to differences in their ability to avoid detection and capture by enforcement agents (Malik 1990).

Individuals responsible for monitoring compliance face their own set of incentives, which may differ from the project implementer's expectations (Tsebelis 1989; Andreozzi 2004). Monitoring incurs opportunity costs, may be dangerous (Hart et al. 1997) and risks inviting recriminations from peers (Robinson et al. 2010), so monitors may face incentives to 'cheat' at their job (such as not patrolling as they are meant to, or failing to report infractions). The position of authority occupied by monitors may also create opportunities for corruption (Mookherjee \& Png 1995). For project implementers, the main tools available to incentivize monitors to perform their duties effectively are the payment of wages and the provision of performance-related bonuses (MestertonGibbons \& Milner-Gulland 1998; Jachmann 2008), but the effectiveness of such payments has received little attention in conservation and remains poorly understood (Mookherjee \& Png 1995; Andreozzi 2004).

Directly studying the interactions between rule-breakers and monitors is both ethically and practically challenging (Baker et al. 2011). Models provide a powerful tool for exploring the implications of assumptions about how people behave, informing the development of hypotheses and fieldbased data collection (Keane et al. 2008). Here we use an individual-based model (IBM) of a community-based conservation project to examine how the incentives faced by potential rule breakers and monitors are affected by payments and sanctions, and how their behaviours interact to determine levels of compliance. IBMs are simulation models that treat individuals as discrete entities with at least one property in addition to age that changes over time (Grimm \& Railsback 2005). They have been widely applied in ecology and are conceptually similar to agent-based models or multi-agent simulation models (Bousquet \& Le Page 2004). IBMs have previously been used in the study of human decision-making and social organization in natural resource management and conservation (Berger 2001; Bousquet 2001; Castella et al. 2005; van Vliet et al. 2010).

The ability of conservation interventions to change behaviour has important social and cultural dimensions, but in this study we focus on their way in which they affect individual incentives. We explore how changes to three policy levers which managers commonly have at their disposal, namely (1) the fine incurred by poachers who are caught, (2) the fees paid to individuals for performing monitoring duties and (3) the size of bonus payments made to monitors for catching a rulebreaker, affect community-level compliance with conservation rules and conservation outcomes via their effects on the behaviour of heterogeneous individual decision-makers. Increases to any of these factors are generally expected to improve compliance (fines by directly increasing the expected costs of rule breaking; fees and bonuses by incentivizing monitors, thereby indirectly increasing the probability that acts of rule breaking are detected). We examine the effect of individual-level heterogeneity on community-level outcomes, expressed as variation in opportunity costs, hunting success and ability to avoid detection. In contrast to other models of enforcement and compliance, our approach allows the functional form of a community's response to policy levers to emerge from the aggregation of individual decisions, rather than being assumed $a$ priori. This leads to testable predictions about the community-level outcomes of commonly used conservation interventions, both separately and in tandem, which can be used to inform the design of incentive-based community conservation interventions.

\section{METHODS}

\section{Model structure}

We modelled a small community-based project intended to reduce poaching of a protected species (see for example Child 1996; Hackel 1999; Holmern et al. 2007). To achieve this, the project provided incentives for community members (1) to refrain from poaching, and (2) to monitor whether others poach, using a combination of rewards and sanctions. Rewards for desirable behaviour included a communitylevel payment, fees for monitoring and bonus payments for reporting poaching. Community payments based on indicators of conservation success are increasingly common in conservation projects (see for example Sommerville et al. 2010) and bonuses for enforcement agents have been widely implemented to improve monitoring effectiveness (see Jachmann 2008). Sanctions include fines for individuals caught poaching and monitors found to be neglecting their duties, which are common to many systems of enforcement. The model draws upon the much simpler analytical model of Mesterton-Gibbons and Milner-Gulland (1998).

The community consisted of $n$ individuals who differed in three respects: (1) their opportunity costs of participating in monitoring and of hunting, (2) their average hunting success (which incorporates hunting effort in the traditional sense of the word, the 'catchability' of their prey and other factors such as their equipment, innate skill and experience), and (3) the degree to which they were willing to invest in avoidance behaviour to reduce their chances of punishment when breaking rules. These characteristics were drawn randomly from normal distributions and were independent of one 
Table 1 Pay-offs to each strategy component. An ' $X$ ' in one of the final six columns indicates that strategy receives the pay-off component. The strategies are denoted by the abbreviations: $\mathrm{PM}=$ poach and monitor; $\mathrm{PC}=$ poach and cheat; $\mathrm{PO}=$ poach and neither monitor nor cheat; $\mathrm{NM}=$ do not poach but monitor; $\mathrm{NC}=$ do not poach but cheat; $\mathrm{NO}=$ do not poach and neither cheat nor monitor.

\begin{tabular}{|c|c|c|c|c|c|c|c|}
\hline \multirow[t]{2}{*}{ Component } & \multirow[t]{2}{*}{ Pay-offequation } & \multicolumn{6}{|c|}{ Strategy } \\
\hline & & $P M$ & $P C$ & $P O$ & $N M$ & $N C$ & NO \\
\hline Community benefit, $W$ & $W=B_{t}$ & $x$ & $\times$ & $x$ & $\times$ & $\times$ & $\times$ \\
\hline Monitor's pay-off, $M$ & $M=Y_{i, t}$ & $x$ & & & $x$ & & \\
\hline Poacher's pay-off, $P$ & $P=\Pi_{i, t}-U_{i, t}-A_{i, t}$ & $\times$ & $\times$ & $\times$ & & & \\
\hline Cheat's pay-off, $C$ & $C=F i, t$ & & $x$ & & & $x$ & \\
\hline Alternative pay-off, $o_{i}$ & $o_{i}$ & & & & & & $x$ \\
\hline
\end{tabular}

another. Once assigned to an individual, they were fixed and did not vary between rounds.

In a given round, each individual adopted one of six strategies resulting from the combination of their monitoring and poaching choices (Table 1). Individuals could poach or not poach, and monitor, cheat (pretend to monitor without performing their duties) or do neither. An individual's success in a round depended upon their strategy choice, the choices of the rest of the population, their individual characteristics and, for poachers, the size of the animal population. We assumed that these strategies required no special skills or investment in particular technologies, so there were no barriers to individuals switching between them. Individuals who neither poached nor monitored were assumed to pursue an alternative livelihood strategy.

\section{Community benefit, $W$}

The community received a payment from an external organization in each round. For the first five rounds this was fixed at its maximum, $B_{\text {max }}$, and each individual received an equal share, $B_{t}$ :

$$
B_{t}=\frac{B_{\max }}{n}
$$

This grace period was intended to ensure that the community benefit was not immediately lost if the model was initiated using a scenario involving high levels of poaching. Subsequently, we reduced the amount paid in proportion to the number of poachers caught in the previous round, $n_{\kappa, t-1}$. The payment per individual was therefore:

$$
B_{t}=\frac{B_{\max }}{n}\left(1-\frac{n_{\kappa, t-1}}{n}\right)
$$

\section{Pay-off from poaching, $P$}

Individual $i$ 's revenue from poaching in round $t, \Pi_{i, t}$, was the product of their catch, $h_{i, t}$, and the revenue per animal, $v$ :

$$
\Pi_{i, t}=v h_{i, t}
$$

The number of animals caught by individual $i$ in round $t$, $h_{i, t}$, was drawn from a Poisson distribution whose mean was the size of the prey population in that round, $X_{t}$ multiplied by the focal individual's average hunting success, $e_{i}$. Only the variable costs of hunting were considered, and were incorporated into the revenue per animal. We assumed the effect of hunting on market supply was negligible and individual effort did not vary, so $v$ was thus constant.

The hunted species' population dynamics were described by a discrete logistic equation. The number of animals in round $t, X_{t}$, was:

$$
X_{t}=X_{t-1}+\rho X_{t-1}\left(1-\frac{X_{t-1}}{K}\right)-\sum_{i=1}^{n} h_{i, t-1}
$$

where $\rho$ is the intrinsic growth rate and $K$ is the environmental carrying capacity.

All poachers risk capture and punishment but can expend resources on avoidance in order to reduce the probability of detection (Malik 1990). Avoidance behaviour has costs (such as time away from hunting or using less noticeable but less efficient equipment). We assumed a fixed cost, $a$, per unit of avoidance behaviour. We assumed that poachers had a sense of the risk involved in poaching, through gossip or a similar mechanism. The total cost of avoidance by individual $i$ in round $t, A_{i, t}$, was therefore a function of the proportion of poachers who were caught in the previous round (representing the perceived current risk of poaching) and the focal individual's 'propensity to avoid detection', $\alpha_{i}$,:

$$
A_{i, t}=a \alpha_{i} \frac{n_{\kappa, t-1}}{n_{P, t-1}}
$$

where $n_{P, t-1}$ was the total number of individuals poaching in the previous round and $n_{\kappa, t-l}$ was the number of individuals caught poaching in the previous round.

The probability that individual $i$ was detected poaching in round $t, d_{i, t}$ reduced as avoidance increased, but with diminishing returns:

$$
d_{i, t}=1-\left(1-\frac{p}{\alpha_{i}\left(\frac{n_{\kappa, t-1}}{n_{P, t-1}}\right)+1}\right)^{n_{M, t}}
$$

where $p$ is the baseline probability that a poacher was detected by any monitor before avoidance was taken into account, and $n_{M, t}$ was the number of monitors in round $t$. 
We assumed that poachers were caught with the animals they had killed in their possession. If a poacher is detected, punishment therefore takes the form of a fine, $u$, per animal caught, which has previously been shown to be more effective than a fixed fine (Milner-Gulland \& Leader-Williams 1992). The fine paid by poacher $i$ in round $t, U_{i, t}$, was:

$$
U_{i, t}= \begin{cases}h_{i, t} u & \text { if caught } \\ 0 & \text { if not caught }\end{cases}
$$

\section{Pay-off from monitoring, $M$}

Monitors received a fee, $f$, per round, but faced a cost of social opprobrium, $s$, proportional to the number of poachers caught during round $t$. This cost reflected the resentment of poachers towards the monitors who had caught them (Robinson et al. 2010). The net gain from monitoring, $Y_{i, t}$, was thus:

$$
Y_{i, t}=f-s n_{\kappa, i, t}
$$

The first individual to report a poaching incident was also paid a bonus, $j$, as an incentive to monitor effectively. The bonuses paid to monitor $i$ in round $t, \mathcal{F}_{i, t}$, were:

$$
\mathcal{F}_{i, t}=j n_{\kappa, i, t}
$$

where $n_{\kappa, i, t}$ is the number of poachers caught by individual $i$ in round $t$.

Pay-off from cheating, $C$

Individuals may also 'cheat' by claiming their fee without performing their duties. Cheating would not incur the social opprobrium of monitoring, but individuals would not earn bonuses and risked punishment if detected. The probability that individual $i$ was caught cheating in round $t, g_{i, t}$, was:

$$
g_{i, t}=1-(1-q)^{n_{M, t}}
$$

where $q$ was the probability that a cheat was detected by any individual monitor.

If caught, cheats lost their monitoring fee for the round and were fined a fixed amount, $k$. The pay-off for cheating in round $t$ for individual $i$ was thus:

$$
F_{i, t}=\left\{\begin{array}{cl}
-k & \text { if caught } \\
f & \text { if not caught }
\end{array}\right.
$$

\section{Pay-off from alternative livelihoods, $o_{i}$}

Strategies involving combinations of poaching, monitoring or cheating were assumed to occupy all of an individual's time. Individuals who did not pursue these activities may instead have adopted other livelihood activities. The pay-off to individual $i$ from alternative livelihood activities was $o_{i}$, and represented their opportunity costs of participating in the wildlife management scheme.

\section{Parameterization and implementation}

We implemented the model using $\mathrm{R}$ version 2.10.1 ( $\mathrm{R}$ Development Core Team 2009). Few data were available to guide the model's parameterization, so we selected baseline parameter values based on exploratory runs to ensure that the system did not lie at the extremes of parameter space (Appendix 1, Table S1, see supplementary material at Journals.cambridge.org/ENC). Similar 'paradigmatic' IBMs (Grimm \& Railsback 2005) have a long history of use in theoretical ecology to explore the consequences of individuallevel processes on patterns at more aggregated levels (see for example lomnicki 1978; Uchmański 1985, 1999; Grimm \& Uchmański 2002).

During a typical model run, the system slowly approached equilibrium, which displayed relatively little variation for a given set of parameter values. Each simulation was therefore allowed to run for 2000 rounds, by which time the system invariably reached equilibrium, and we averaged the results over five repeats to reduce the effects of minor stochastic differences between runs.

The community was not subject to immigration or emigration so remained constant at 498 individuals, a realistic size for a small community. At the beginning of a run, individuals were assigned evenly to the six strategies available for the purposes of initialization. After each round, we calculated individual pay-offs, and the 30 people receiving the lowest pay-off were allowed to change their strategy. Twenty-four were randomly assigned one of the strategies adopted by the 24 most successful individuals, while the remaining six chose a new strategy at random. This was designed to reflect a process whereby individuals strive to emulate their more successful peers based on imperfect knowledge about the success of different strategies. The differing pay-offs between individuals and assigning a random choice of strategy to a small number of individuals ensured that the model did not settle at local optima. We used preliminary sensitivity analyses to verify that the model outputs were robust to moderate changes in the initial strategy distribution and the number of individuals changing strategy per round.

\section{Analyses}

Our analyses sought to test how changes to the three policy levers under consideration affected levels of poaching and monitoring within the community, as well as the conservation outcome of the size of the animal population. First, the behaviour of the system was determined for a baseline scenario, in which the level of the intervention was as low as possible (namely no fines, and no expenditure on paying either fees or bonuses to monitors). Next, we modelled a series of scenarios corresponding to the use of one or more of the policy levers to encourage monitoring and discourage poaching (Appendix 1, Table S2, see supplementary material at Journals.cambridge.org/ENC). 


\section{RESULTS}

\section{'Zero-enforcement' baseline}

With no fines for poaching and no resources devoted to encouraging monitoring (Scenario 1), poaching strategies dominate. At equilibrium, the animal population was approximately $38 \%$ of carrying capacity (Fig. 1). Few individuals monitored, so the probability that poachers were detected was small. The majority of individuals therefore spent their time poaching, while a smaller group pursued alternative livelihoods because their opportunity costs outweighed the revenues they received from poaching, which were a function of both the animal population size $X_{t}$ and their hunting success, $e_{i}$.

\section{Enforcement scenarios}

In a scenario where only fines were implemented (Scenario 2), approximately half of the community poached. Others pursued alternative livelihoods because the risk of fines reduced the relative profitability of poaching. Few individuals adopted a monitoring strategy, so there was only a small increase in the probability that poachers were detected, but this was enough to reduce the number of individuals poaching, such that the equilibrium animal population increased to $62 \%$ of carrying capacity.

By contrast, the payment of fees or bonuses for monitoring, separately or together, did not affect the equilibrium animal population in the absence of fines. Paying fees alone (Scenario 3) raised the proportion of poachers who also cheated, but produced only a small increase in the number of monitors. The scarcity of monitors meant that cheats were unlikely to be detected and, in the absence of this deterrent, the cost of social opprobrium for monitors outweighed the potential rewards from bonus payments. The pay-off for cheating also made cheating and poaching more profitable than alternative livelihoods for many individuals. The payment of bonuses (Scenario 4) increased the proportion of the community who both poached and monitored, resulting in a higher probability that poachers were detected, but remaining insufficient for the strategy of monitoring without poaching to become profitable for any individual. The pattern was similar when both fees and bonuses were paid (Scenario 7), with further increases in the number of individuals who both poached and monitored and in the probability that poachers were detected. Although scenarios in which fees or bonuses were paid without the imposition of fines for poaching (Scenarios 3,4 and 7) produced a rise in the probability of detecting poachers, poaching was not discouraged, because there were no consequences for poachers who were caught. Consequently none of these scenarios caused a change in the overall number of poachers or the equilibrium animal population (Fig. 1).

Counterintuitively, the implementation of fines and fees together (Scenario 5) resulted in a lower probability of detecting poaching and smaller equilibrium resource population than using fines alone (Scenario 2). This occurred
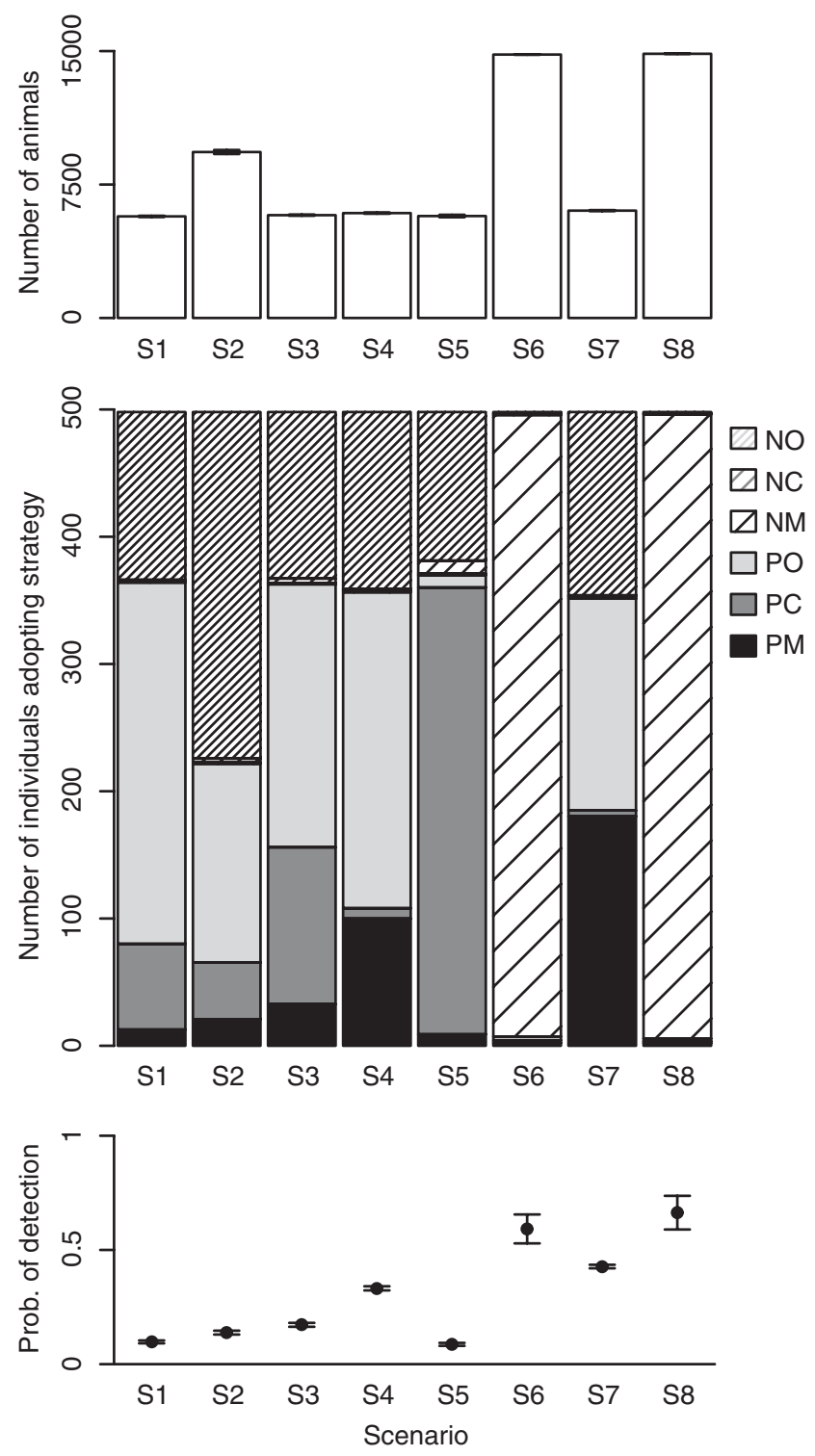

Figure 1 Comparison of a 'zero enforcement' baseline (Scenario 1 [S1]) with scenarios (S2-S8) where different combinations of fines for poaching and fees and bonuses for monitoring are used to encourage compliance (Appendix 1, Table S2 provides details of the scenarios, see supplementary material at

Journals.cambridge.org/ENC). Top: the equilibrium animal population under each scenario; middle: the proportion of the community that adopts each strategy; and bottom: the resultant probability (prob.) that poachers are detected, with error bars indicating the range within which $95 \%$ of simulations fell. The strategies adopted are denoted by the following abbreviations: $\mathrm{NO}=$ pursue alternative livelihoods, neither poaching nor monitoring; $\mathrm{NC}=$ do not poach and cheat at monitoring; $\mathrm{NM}=$ do not poach but monitor; $\mathrm{PO}=$ poach and neither monitor nor cheat; $\mathrm{PC}=$ poach and cheat at monitoring; $\mathrm{PM}=$ poach and monitor.

because the majority of the community chose to poach and cheat. The payment of fees increased the returns to both monitoring and cheating strategies, but only monitoring 
strategies incurred the costs of social opprobrium and only cheats bore the costs of punishment if they were caught. In Scenario 3, where only fees were implemented, a large number of poachers chose to neither monitor nor cheat to avoid these costs. However, the addition of fines for poaching reduced the returns to poaching. Monitoring remained unprofitable because of the costs of social opprobrium, so, in Scenario 5, the balance of incentives was tipped in favour of cheating.

By contrast, scenarios with fines and bonuses together (Scenario 6) or fines, bonuses and fees (Scenario 8) were dramatically different, with virtually the entire community refraining from poaching and monitoring the behaviour of others. In these scenarios, the payment of bonuses to monitors outweighed the effects of social opprobrium, and the imposition of fines reduced the returns to poaching, making the strategy that conservationists were aiming for (monitoring and not poaching) the most profitable for all individuals. Under both scenarios, the probability of detecting poaching was high and the resource population was close to carrying capacity.

\section{Effects of varying policy levers}

Changes to each of the policy levers may affect the probability that poachers are detected, the proportion of the community that monitors and the size of the resource population. The specific responses to these changes vary between the policy levers and according to the economic context in which they are used.

The probability of detecting poachers showed two distinct regions, depending on the level of fine per animal. Above a threshold fine level, the probability of detection was quite variable, but did not respond to changes in either the fees or bonuses paid to monitors. Below the threshold fine level, however, the probability of detection rose steadily with both fees and bonuses (Fig. 2a-c). These changes were only partially reflected in the size of the resource population (Fig. $2 d-f$ ). Again, two regions of distinct behaviour could be distinguished, above and below a threshold fine level. Unlike probability of detection, however, the sizes of the monitoring fees and bonuses paid only had a significant influence on the resource population at intermediate fine levels. Here, the effects of small changes to bonuses and fees were ambiguous and could produce either increases or decreases in the resource population.

Two examples illustrate the potential for perverse effects caused by raising the fees and bonuses paid to monitors (Fig. 3). The strategy set and outcome variables for an intermediate level of fine, relatively low fees and profitable alternative livelihoods varied as bonuses increased (Fig. $3 a$ ). When no bonuses were paid, a high proportion of the community poached and cheated. Initially, the number of cheats declined and disappeared as bonuses were increased, with some individuals poaching and monitoring, but the majority pursuing alternative livelihoods. However, further increases in bonuses were counterproductive, as the strategy of poaching and monitoring became more profitable and was adopted by an increasing proportion of the community; as the number of poachers began to rise again, the resource population declined. Finally, at higher bonus levels, monitoring without poaching became profitable, and began to replace both the poaching and monitoring, and alternative livelihoods strategies.

Increases in the size of monitoring fees, given an intermediate fine for poaching but no bonuses paid to monitors, produced similar results (Fig. $3 b$ ). When no fees were paid, the community was split between the three poaching strategies and alternative livelihoods. In this case, raising the fee initially led to increased poaching, with the majority poaching and cheating. Since the probability of being caught cheating or poaching was small, the payment of a small monitoring fee improved the profitability of poaching and cheating, effectively subsidizing poaching, and the resource population fell. Further increases in the fee eventually tipped the balance in favour of monitoring, with the majority of the community also stopping poaching.

\section{Influence of external factors on policy levers' effects}

The results of changes to the three policy levers also depend on the context in which they are applied. One important influence is the value of the resource to poachers. Increases or decreases in the returns to poaching shift the threshold fine level higher and lower respectively, with the threshold occurring approximately at the point where the returns per animal killed are equal to the fine for poaching.

Differences in the ease of detecting cheats primarily affected the system's response to fees. For example, when it was very difficult to detect cheats, the range over which increases in fees perversely reduce the resource population became much larger (Fig. 4a). By contrast, there were no perverse effects of paying fees when cheats were easily detected (Fig. $4 c$ ).

Changes in the average pay-off for alternative livelihoods modified the effects of all three policy levers. For example, alternative livelihoods produced low profits, and increases in the size of bonus payments rapidly increased the resource population. Increases to the size of the monitoring fee may initially have a perverse effect, producing a large fall in the resource population because cheating, rather than monitoring, is favoured, reducing the threat of punishment for poachers. When the profitability of alternative livelihoods increased, increases to the size of bonus payments produced a slower increase in the size of the resource population because bonuses must be much higher for monitoring to be favoured. In addition, when alternative livelihoods were more profitable, the region over which increasing the payment of fees produces perverse effects became smaller and ultimately disappeared.

\section{DISCUSSION}

Changing people's behaviour is an important goal of many conservation interventions (St John et al. 2010). Over time, 

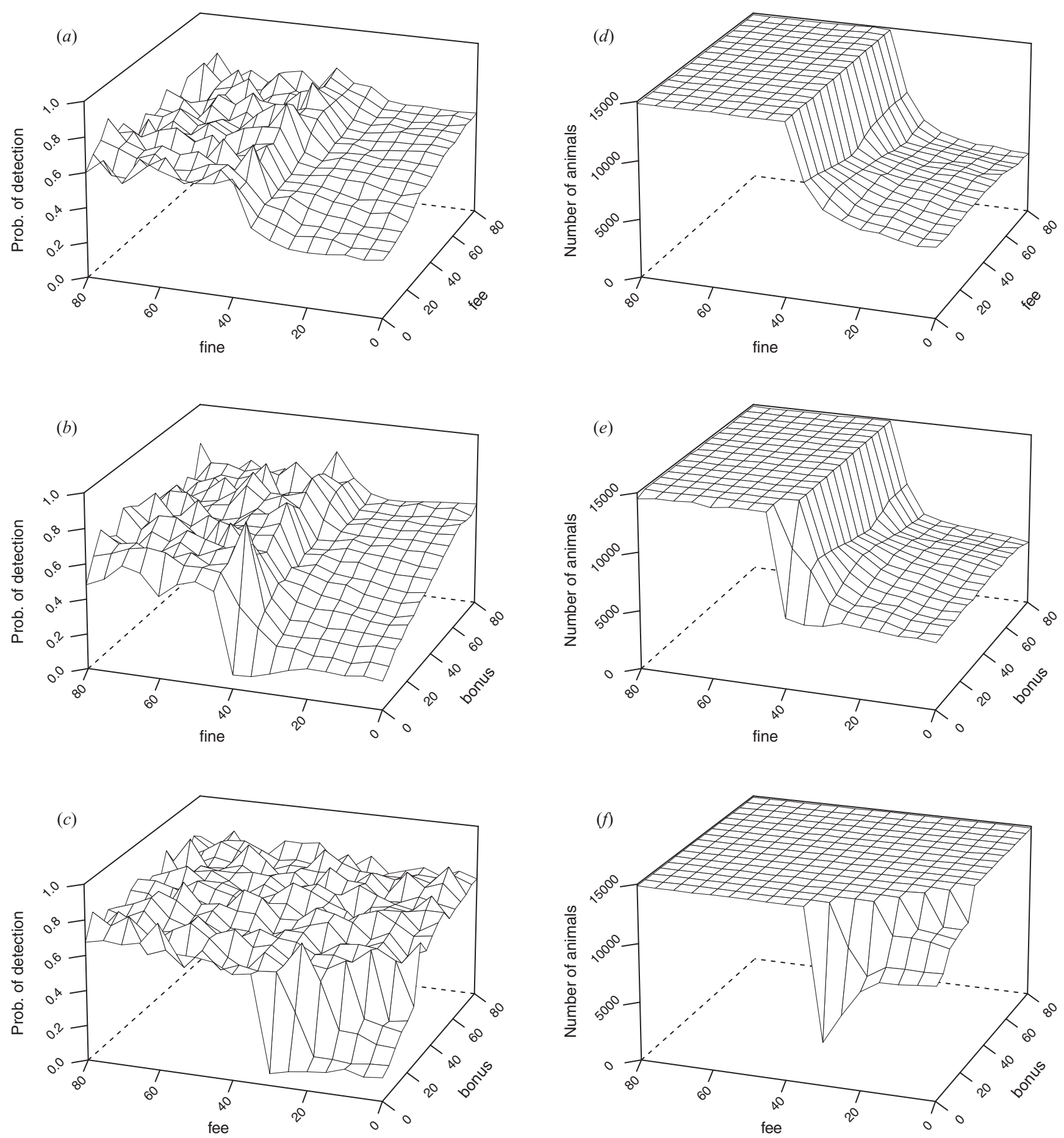

Figure 2 Changes in $(a-c)$ the probability (prob.) that poachers are detected and $(d-f)$ the size of the equilibrium resource population in response to changes in pairs of the three policy levers. The values of all other parameters, including the third policy lever, are held at their baseline levels (Appendix 1, Table S1, see supplementary material at Journals.cambridge.org/ENC). Points on the surfaces represent the state of the system when the focal policy levers are set at a specific pair of values and connecting lines indicate examples of how the system state changes in response to changes in a single policy lever, with all other factors held constant.

the emphasis on how to achieve this has shifted from the enforcement of strictly protected areas (Oates 1999), to community-based participatory conservation (Lewis et al. 1990) and, more recently, the potential of PES (Ferraro
2002; Engel et al. 2008). However, these approaches share considerable common ground, since they all represent strategies for changing individual incentives to abide by rules or agreements. Understanding these incentives, and how they 
(a)
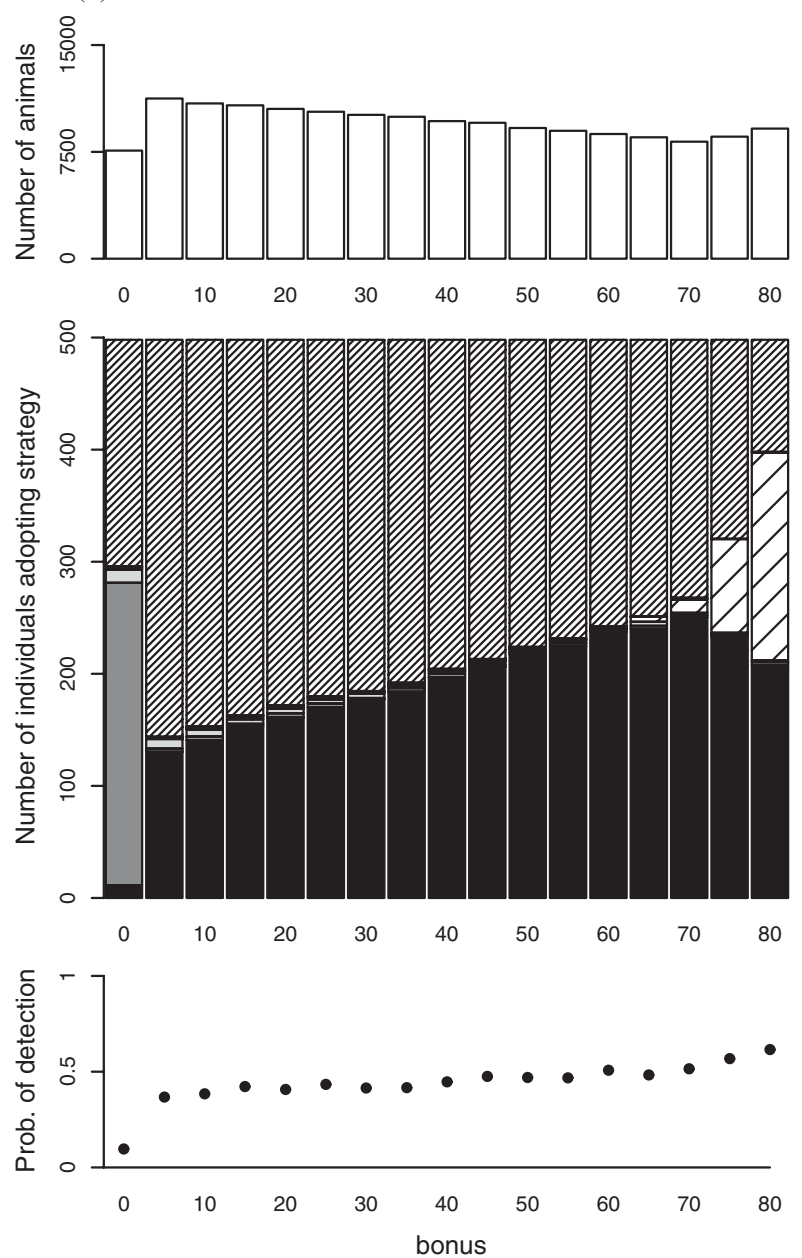

(b)
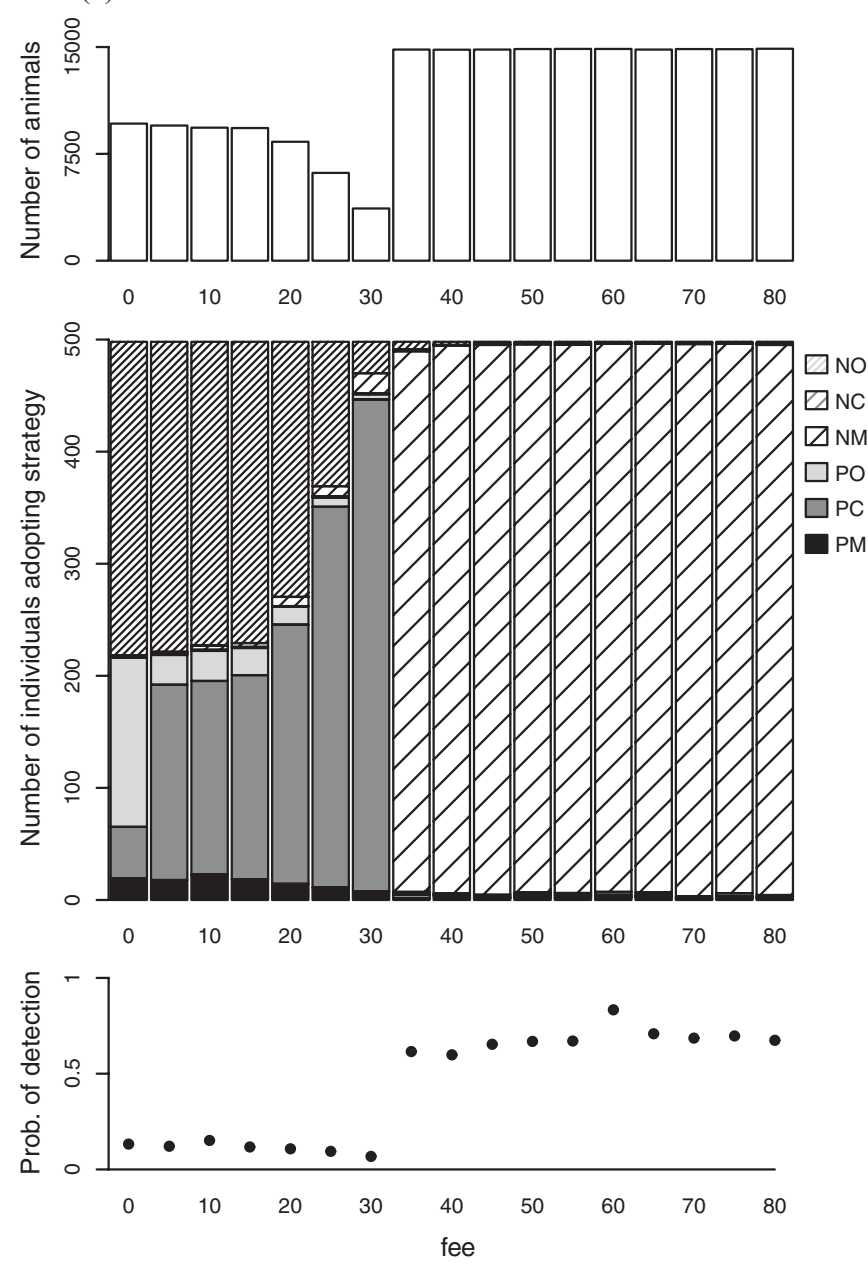

Figure 3 Examples illustrating the potential for perverse effects of payments intended to increase compliance by encouraging monitoring. (a) Effects of increasing the size of bonus $(j)$ paid to monitors given an intermediate fine for poaching $(k=35)$, and relatively low fee $(f=25)$ paid to monitors and higher mean pay-offs for alternative livelihoods (mean $\left.o_{i}=40\right)$. $(b)$ Effects of increasing the size of fee $(f)$ paid to monitors given intermediate fines $(k=40)$ for poaching, but no bonus paid to monitors $(j=0)$. Top: the equilibrium animal population under each scenario; middle: the proportion of the community that adopts each strategy; and bottom: the resultant probability (prob.) that poachers are detected. The strategies adopted are denoted by the following abbreviations: NO = pursue alternative livelihoods, neither poaching nor monitoring; $\mathrm{NC}=$ do not poach and cheat at monitoring; $\mathrm{NM}=$ do not poach but monitor; $\mathrm{PO}=$ poach and neither monitor nor cheat; $\mathrm{PC}=$ poach and cheat at monitoring; $\mathrm{PM}=$ poach and monitor.

can be modified in beneficial ways, has increasingly been recognized as crucial for effective conservation, particularly in the literature on market-based instruments (Ferraro 2002; Engel et al. 2008; Sommerville et al. 2009).

Previous studies examining the enforcement of resourceuse rules have tended to concentrate on the users' incentives (for example fishers or poachers; Leader-Williams \& MilnerGulland 1993; Skonhoft \& Solstad 1996; Damania et al. 2005). However, the success of enforcement also depends crucially on monitors' incentives to carry out their duties (Mookherjee \& Png 1995; Mesterton-Gibbons \& Milner-Gulland 1998; Robinson et al. 2010). The model presented here explores the effects on conservation outcomes of changes to three potential policy levers intended to promote monitoring and discourage poaching. Within the region of parameter space explored, we found that increasing the fine per animal for poachers was generally the most robust tool for improving outcomes. However, this finding must be weighed against the disadvantages of high fines. Early economic models of crime and enforcement saw changes to the probability that rule breakers were detected and punished, and the severity of subsequent penalties as having equivalent effects on deterrence. From this, it was concluded that an optimal enforcement strategy would raise fines as high as possible (since this was seen as costless), so that the deterrent effect upon rule-breaking could be maintained with lower levels of costly monitoring (Becker 1968). Subsequently, however, many extensions to Becker's model demonstrated why fines cannot, in practice, be set at very high levels (Garoupa 1997; Keane et al. 2008; Robinson et al. 2010). In conservation, 
(a)
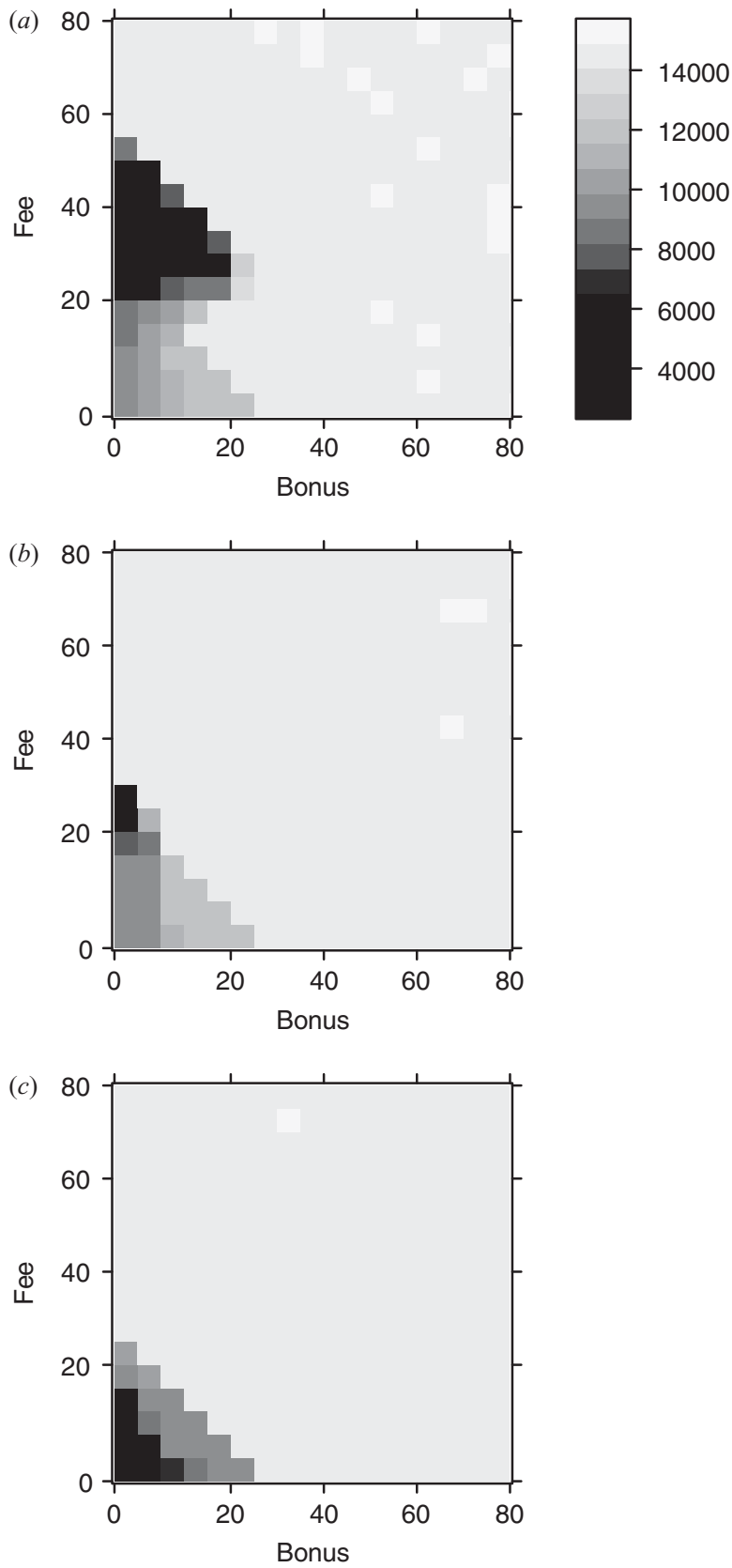

Figure 4 The effect on the equilibrium animal population of changing the size of fees and bonuses paid to monitors for three scenarios, differing according to the ease of detecting cheats, $q$. The scenarios are $(a) q=0.002,(b) q=0.01$, and $(c) q=0.05$. All other parameters values are held at their baseline levels (Appendix 1, Table S1, see supplementary material at Journals.cambridge.org/ ENC). Larger equilibrium animal populations are indicated by lighter grey cells, while smaller populations are indicated by darker cells (see key to the side of the figure). Perverse effects can be seen where increasing either fee or bonus level leads to a smaller animal population (namely, darker cells).

'fences and fines' approaches have gradually fallen out of favour (Oates 1999) and harsh enforcement regimes may undermine relationships between conservation and local people (see Infield \& Namara 2001; Wilshusen et al. 2002).
In our system, increases in the size of fees and bonuses paid to monitors generally produced smaller changes than increases in fines, and, in some cases, led to perverse effects. Mesterton-Gibbons and Milner-Gulland (1998) found that the payment of fees was essential for the stability of monitoring as a strategy. The discrepancy between this finding and ours results from differences in the range of behaviours which modelled individuals were allowed to adopt. In particular, we considered an additional component to individuals' strategies (cheating) and allowed poachers to invest in avoidance to reduce their risk of being detected and punished. Both of these behaviours are commonly observed in practice (see Malik 1990; Polinsky \& Shavell 2001; Randall 2004).

In our model, fines are a more robust strategy than fees and bonuses because their effect is more direct; raising the level of fines in the model always lowers the average profitability of poaching. By contrast, the payment of fees or bonuses can lead to more poaching in certain circumstances, because both payments increase the profitability of monitoring both for individuals who poach as well as those that do not, so do not necessarily favour monitoring without poaching over monitoring and poaching. Similarly, the payment of fees can encourage monitoring, but where cheating is hard to detect it may be more profitable than actually monitoring. An individual's additional income from monitoring fees can therefore increase the profitability of strategies that include poaching, resulting in individuals switching from nonpoaching to poaching strategies.

Our approach highlights an important limitation of models of optimal enforcement, in which the severity of sanctions and the probability of detection have generally been discussed as separate inputs (see for example Becker 1968; Milner-Gulland \& Leader-Williams 1992; Garoupa 1997). Where decisions are strategic, we found that the probability of detection experienced by rule breakers can be partially determined by the level of the fine, rather than the two being independent. This can occur because higher fines for poachers reduce the profitability of poaching relative to other strategies. When the returns to alternative livelihoods are low, the most profitable strategy is then not to poach, but to monitor, increasing the probability that poaching and cheating are detected. This interdependence between the probability of detection and fine level is likely to be particularly pronounced where monitors are recruited from small communities with few other livelihood options. A formal optimization of enforcement strategies based on our model is beyond the scope of this investigation, but this result suggests that such interactions should be carefully accounted for in the design of conservation interventions. If the probability of detecting rule-breaking and the severity of sanctions are jointly determined, models that assume that they are independent would tend to overestimate the investment in enforcement needed to produce a desired level of compliance.

Finally, this study emphasizes the importance of context and individual heterogeneity in determining the effectiveness of management interventions. In particular, we found that different approaches to modifying incentives may interact 
with one another in communities where individuals differ in their underlying skills and characteristics. The outcome of changes to the three policy levers depended strongly on their interactions with one another, and on the broader socioeconomic and ecological context in which they were embedded. With the prospect of many more PES schemes being implemented (Engel et al. 2008; Wunder et al. 2008), there is an urgent need to understand how such novel incentive structures will interact with existing institutions. Analyses on simulated systems, such as the one presented here, allow manipulations that would be unethical and challenging to perform in the real world, and enable thorough exploration of system behaviour. However they should be seen only as a starting point for empirical investigations. Our model relies on a number of assumptions that we were not able to test. While the behaviours and strategies represented are commonly observed, the choice of parameter values and structural relationships were assumed and different choices would likely have affected the detailed content of our results. In reality, community-based enforcement systems may be even more complex than the system we depict, with community monitors receiving assistance from government officials, local police and research staff (Milne \& Niesten 2009). Research is needed to understand the true functional forms of the key behavioural relationships captured in our models and to determine which characteristics of individuals and populations must be included in models of human behaviour if they are to inform robust decision making (Keane et al. 2008). One promising avenue for addressing these questions is taking an experimental approach to understanding behaviour; this is increasingly being done in conservation (see Travers et al. 2011). Conservation practitioners are now able to choose from a broad range of approaches to managing human behaviour, including enforcement, education, alternative livelihood strategies and direct payment schemes. If interventions are to be successful, these choices must ultimately be grounded in a unified theoretical framework of incentives at the individual level.

\section{ACKNOWLEDGEMENTS}

We are grateful to the Leverhulme Trust, the Economic and Social Research Council (to Aidan Keane) and a Royal Society Wolfson Research Merit Award (to E. J. Milner-Gulland) for funding this research.

\section{References}

Agrawal, A. \& Gibson, C.C. (1999) Enchantment and disenchantment: the role of community in natural resource conservation. World Development 27: 629-649.

Akella, A.S. \& Canon, J.B. (2004) Strengthening the weakest link. Strategies for improving the enforcement of environmental laws globally. Report. CCG Reports, Centre for Conservation and Governance at Conservation International, Washington,
DC, USA [www document]. URL http://www.illegal-logging. info/uploads/Weakest_Links_-_Conservation_International.pdf Andreozzi, L. (2004) Rewarding policemen increases crime. Another surprising result from the inspection game. Public Choice 121: 6982.

Baker, J., Milner-Gulland, E.J. \& Leader-Williams, N. (2011) Park gazettement and integrated conservation and development as factors in community conflict at Bwindi Impenetrable Forest, Uganda. Conservation Biology 26: 160-170.

Becker, G.S. (1968) Crime and punishment: an economic approach. Fournal of Political Economy 76: 169-217.

Berger, T. (2001) Agent-based spatial models applied to agriculture: a simulation tool for technology diffusion, resource use changes and policy analysis. Agricultural Economics 25: 245-260.

Berkes, F. (2004) Rethinking community-based conservation. Conservation Biology 18: 621-630.

Bousquet, F. (2001) Multiagent simulations of hunting wild meat in a village in eastern Cameroon. Ecological Modelling 138: 331-346.

Bousquet, F. \& Le Page, C. (2004) Multi-agent simulations and ecosystem management: a review. Ecological Modelling 176: 313332.

Castella, J., Boissau, S., Trung, T. \& Quang, D. (2005) Agrarian transition and lowland-upland interactions in mountain areas in northern Vietnam: application of a multi-agent simulation model. Agricultural Systems 86: 312-332.

Child, B. (1996) The practice and principles of community-based wildlife management in Zimbabwe: the CAMPFIRE programme. Biodiversity and Conservation 5: 369-398.

Damania, R., Milner-Gulland, E.J. \& Crookes, D.J. (2005) A bioeconomic analysis of bushmeat hunting. Proceedings of the Royal Society B: Biological Sciences 272: 259-266.

Engel, S., Pagiola, S. \& Wunder, S. (2008) Designing payments for environmental services in theory and practice: an overview of the issues. Ecological Economics 65: 663-674.

Ferraro, P. (2002) The local costs of establishing protected areas in low-income nations: Ranomafana National Park, Madagascar. Ecological Economics 43: 261-275.

Garoupa, N. (1997) The theory of optimal law enforcement. Fournal of Economic Surveys 11: 267-295.

Gibson, C. \& Marks, S.A. (1995) Transforming rural hunters into conservationists: an assessment of community-based wildlife management programs in Africa. World Development, 23, 941957.

Gibson, C.C., Williams, J.T. \& Ostrom, E. (2005) Local enforcement and better forests. World Development 33: 273-284.

Grimm, V. \& Railsback, S.F. (2005) Individual-Based Modeling and Ecology. Princeton Series in Theoretical and Computational Ecology. Princeton, USA and Oxford, UK: Princeton University Press.

Grimm, V. \& Uchmański, J. (2002) Individual variability and population regulation: a model of the significance of withingeneration density dependence. Oecologia 131: 196-202.

Hackel, J.D. (1999) Community conservation and the future of Africa's wildlife. Conservation Biology 13: 726-734.

Hart, T., Hart, J., Fimbel, C., Fimbel, R., Laurance, W.F., Oren, C., Struhsaker, T.T., Rosenbaum, H.C., Walsh, P.D., Razafindrakoto, Y., Vely, M. \& DeSalle, R. (1997) Conservation and civil strife: two perspectives from Central Africa. Conservation Biology 11: 308-314.

Hill, K. \& Kintigh, K. (2009) Can anthropologists distinguish good and poor hunters? Implications for hunting hypotheses, sharing 
conventions, and cultural transmission. Current Anthropology 50: 369-378.

Holmern, T., Muya, J. \& Røskaft, E. (2007) Local law enforcement and illegal bushmeat hunting outside the Serengeti National Park, Tanzania. Environmental Conservation 34: 55-63.

Infield, M. \& Namara, A. (2001) Community attitudes and behaviour towards conservation: an assessment of a community conservation programme around Lake Mburo National Park, Uganda. Oryx 35: 48-60.

Jachmann, H. (2008) Monitoring law-enforcement performance in nine protected areas in Ghana. Biological Conservation 141: 89-99.

Keane, A., Jones, J.P.G., Edwards-Jones, G. \& Milner-Gulland, E.J. (2008) The sleeping policeman: understanding issues of enforcement and compliance in conservation. Animal Conservation 11: 75-82.

Kümpel, N.F., Rowcliffe, J.M., Cowlishaw, G. \& Milner-Gulland, E.J. (2009) Trapper profiles and strategies: insights into sustainability from hunter behaviour. Animal Conservation 12: 531-539.

Leader-Williams, N. \& Milner-Gulland, E.J. (1993) Policies for the enforcement of wildlife laws: the balance between detection and penalties in Luangwa Valley, Zambia. Conservation Biology 7: 611617.

Lewis, D., Kaweche, G.B. \& Mwenya, A. (1990) Wildlife conservation outside protected areas: lessons from an experiment in Zambia. Conservation Biology 4: 171-180.

łomnicki, A. (1978) Individual differences between animals and the natural regulation of their numbers. Fournal of Animal Ecology 47: 461-475.

Malik, A.S. (1990) Avoidance, screening and optimum enforcement. The RAND Fournal of Economics 21: 341-353.

Mesterton-Gibbons, M. \& Milner-Gulland, E.J. (1998) On the strategic stability of monitoring: implications for cooperative wildlife programmes in Africa. Proceedings of the Royal Society of London. Series B: Biological Sciences 265: 1237-1244.

Milne, S. \& Niesten, E. (2009) Direct payments for biodiversity conservation in developing countries: practical insights for design and implementation. Oryx 43: 530-541.

Milner-Gulland, E.J. \& Leader-Williams, N. (1992) A model of incentives for the illegal exploitation of black rhinos and elephants: poaching pays in Luangwa Valley, Zambia. Fournal of Applied Ecology 29: 388-401.

Mookherjee, D. \& Png, I.P.L. (1995) Corruptible law enforcers: how should they be compensated? The Economic fournal 105: 145-159.

Muchaal, P.K. \& Ngandjui, G. (1999) Impact of village hunting on wildlife populations in the Western Dja Reserve, Cameroon. Conservation Biology 13: 385-396.

Oates, J.F. (1999) Myth and Reality in the Rain Forest: How Conservation Strategies Are Failing in West Africa. First edition. Berkeley \& Los Angeles, CA, USA: University of California Press. Ostrom, E. (1990) Governing the Commons: The Evolution of Institutions for Collective Action. Cambridge, UK: Cambridge University Press.
Polinsky, A.M. \& Shavell, S. (2001) Corruption and optimal law enforcement. Fournal of Public Economics 81: 1-24.

R Development Core Team (2009) R: A language and environment for statistical computing [www document]. URL http://www.Rproject.org

Randall, J.K. (2004) Improving compliance in US federal fisheries: an enforcement agency perspective. Ocean Development and International Law 35: 287-317.

Robinson, E.J.Z., Kumar, A.M. \& Albers, H.J. (2010) Protecting developing countries' forests: enforcement in theory and practice. Fournal of Natural Resources Policy Research 2: 25-38.

Skonhoft, A. \& Solstad, J.T. (1996) Wildlife management, illegal hunting and conflicts. a bioeconomic analysis. Environment and Development Economics 1: 165-181.

Sommerville, M.M., Jones, J.P.G. \& Milner-Gulland, E.J. (2009) A revised conceptual framework for payments for environmental services. Ecology and Society 14(2): 34 [www document]. URL http://www.ecologyandsociety.org/vol14/iss2/art34/

Sommerville, M.M., Jones, J.P.G., Rahajaharison, M. \& MilnerGulland, E.J. (2010) Impact of a community-based payment for ecosystem services intervention on forest use in Mebabe, Madagascar. Conservation Biology 24: 1488-1498.

St John, F.A.V., Edwards-Jones, G. \& Jones, J.P.G. (2010) Conservation and human behaviour: lessons from social psychology. Wildlife Research 37: 658-667.

Travers, H., Clements, T., Keane, A. \& Milner-Gulland, E.J. (2011) Incentives for cooperation: the effects of institutional controls on common pool resource extraction in Cambodia. Ecological Economics 71: 151-161.

Tsebelis, G. (1989) The abuse of probability in political analysis: the Robinson Crusoe fallacy. The American Political Science Reviem 83: 77-91.

Uchmański, J. (1985) Differentiation and frequency distributions of body weights in plants and animals. Philosophical Transactions of the Royal Society of London. B, Biological Sciences 310: 1-75.

Uchmański, J. (1999) What promotes persistence of a single population: an individual-based model. Ecological Modelling 115 : 227-241.

van Vliet, N., Milner-Gulland, E.J., Bousquet, F., Saqalli, M. \& Nasi, R. (2010) The effect of small-scale heterogeneity in prey and hunter distributions on the sustainability of bushmeat hunting. Conservation Biology 24: 1327-1337.

Walker, R. (2002) Age-dependency in hunting ability among the Ache of Eastern Paraguay. Fournal of Human Evolution 42: 639657.

Wilshusen, P.R., Brechin, S.R., Fortwangler, C.L. \& West, P.C. (2002) Reinventing a square wheel: critique of a resurgent 'protection paradigm' in international biodiversity conservation. Society and Natural Resources: An International fournal 15: 17-40. Wunder, S., Engel, S. \& Pagiola, S. (2008) Taking stock: a comparative analysis of payments for environmental services programs in developed and developing countries. Ecological Economics 65: 834-852. 